\title{
Assessing the clinical ethical competence of undergraduate medical students
}

Kenneth R Mitchell, Catherine Myser and Ian H Kerridge Faculty of Medicine, University of Newcastle, Australia

\section{Authors' abstract}

At the University of Newcastle, health law and ethics is taught and assessed in each year of the five-year curriculum. However, the critical question for assessment remains: 'Does teaching ethics have a measurable effect on the clinical activity of medical students who have had such courses?' Those responsible for teaching confront this question each year they sit down to construct their assessment tools. Should they assess what the student knows? Should they assess the student's moral reasoning, that is, what decisions the student makes, and, how these decisions are justified, or, should they assess what the student actually does when dealing with patients in the clinical setting, and how he or she does it? From 1982 to 1991, assessment at Newcastle was primarily aimed at determining the quality of the students' ethics knowledge base. This paper describes the strengths and limitations of a purely knowledgebased method of evaluation and why in 1992, we are now attempting to redefine and assess, what we call 'clinical ethical competence' in terms of how students actually apply this knowledge base in a controlled clinical context.

\section{Introduction}

The Pond Report (1) has recommended that some form of compulsory examination be undertaken at the undergraduate level to assess each medical student's ability to reason critically and logically about ethical issues. Compulsory assessment of medical ethics is still a relatively contentious issue and it has been argued that failure to do so would be interpreted as an indication of the relative unimportance that faculty attaches to ethics as a subject (2). The absence of a formal assessment in ethics not only tends to downgrade the course but inevitably leads to its being classified as 'voluntary', either officially or at least in the perception of students. The

\section{Key words}

Teaching medical ethics; health law and ethics; undergraduate medical education; clinical ethical competence; assessing clinical ethical competence; Australia. fate of an ethics course that is either compulsory but not examined (3), or both voluntary and nonexaminable (4), is poor attendance and the uncertain acquisition of important clinical skills.

Curriculum content and educational methodology have been the focus of several papers published in recent years $(2,3,5,6,7)$. To date though, there has been insufficient focus on: a) what minimal knowledge or skills should be taught to students to ensure clinical ethical competence; and b) how these multiple components of clinical ethical competence can or should be assessed. Interest in multi-assessment strategies has therefore been slow to develop, which may partly explain why compulsory teaching and assessment of ethics remain contentious issues.

\section{The Newcastle health law and ethics strand}

The University of Newcastle's undergraduate medical curriculum is problem-based, communityoriented and organised into five domains: 1 ) professional skills; 2) critical reasoning; 3) management of illness; 4) population medicine, and 5) self-directed learning. Health law and ethics (HLE) is integrated within domain 3 and has evolved over 15 years into three basic components. These components are:

1. A formal classroom course which began in 1979, and now comprises $28 \times 1 \frac{1}{2} 2$ hour seminars and associated small-group discussions (42 hours total), provides the fundamental theories, principles, concepts and related knowledge framework necessary for ethical and legal reasoning and decision-making (8). Because HLE is perceived as an important part of clinical reasoning and practice, it has been integrated with clinical problem-based learning and spread throughout all five years of the undergraduate programme, with different principles and concepts being emphasised in different years (8).

2. A clinical ethics course which is integrated with the clinical attachments in years four and five, the main aim of which is to improve the quality of students' care for patients. This course, which began in 1991, is still being developed and is in the process 
of expanding to include attachments in geriatrics, palliative care, ICU, paediatrics, obstetrics and psychiatry. These attachments provide opportunities for students to consolidate and build on their classroom-acquired knowledge base, and will enable them to receive broader clinical supervision in the application of learnt ethical principles to actual ongoing cases. More specifically, the clinical rotations serve to reinforce previously learnt interactional skills and ethical sensitivity (9), as well as providing a clinical context in which to teach clinical-ethical reasoning and demonstrate its relevance to everyday medicine. Through this experience, students begin to learn how actual: 1) medical circumstances, 2) interactions with patients and other health-care professionals, 3) possible differing values of patients and various health-care professionals, and 4) time and other constraints influence clinical ethical analysis and decision-making. It is precisely this potent intermingling of the technical, contextual, personal and moral dimensions of shared decision-making that we and others regard as a fertile base for student learning $(10,11)$.

3. In 1992, the third and most recent basic component of the HLE strand was introduced to focus specifically on the skills associated with clinicalethical reasoning and decision-making. A central feature of these skill sessions is their emphasis on clinical ethical competence as a professional skill. They were introduced into the year-four curriculum (initially) to overcome problems experienced by some students in integrating the cognitive and theoretical aspects of ethical reasoning with the clinical management of patients. The latter requires the application of medical science to the patient's condition and the former requires an ethically justifiable argument, to ensure that clinical decisions are both technically correct and ethically defensible. Medical science identifies what can be done and ethics gives guidance as to what ought to be done (11). Specifically, the students present cases and are taught how to: 1) identify and anticipate ethical issues, distinguishing them from legal and social issues; 2) determine which bioethical principles and concepts are relevant, where they clash and why; and, 3) state their clinical ethical decision, specifying how the guiding principles should be balanced, and justifying their arguments and decisions.

\section{Assessment pre-1992 at Newcastle}

End-of-year assessments, usually lasting 30 minutes, were carried out in all years of the curriculum. Faculty policy regards failure in the HLE strand in the same way as failure in any other basic science or clinical discipline. The question of how HLE should be assessed was determined by the examination strategy adopted for most of the written assessments for clinical medicine, namely, the modified essay question (MEQ). The MEQ is essentially the step- $\stackrel{\square}{\longrightarrow}$ by-step unfolding of a clinical case. For each step $\overrightarrow{\bar{\sigma}}$. students are required to provide answers to questions of 5 , or 10 or sometimes 15 -minute durations, $\vec{F}$ with each 5-minute 'chunk' being equivalent to one $\stackrel{\text { ? }}{+}$ mark. Students are not permitted to turn back having completed a step and moved on. Table $1 \frac{\bar{\sigma}}{\bar{\rho}}$ illustrates the clinical case and questions used to $\frac{\rho}{\sigma}$ assess year-five students in 1991. Questions 1 and $2 \varrho$ covered palliative issues to do with dyspnoea. (These $ळ$ are not shown in the table.)

Model answers are written and assessors identi- fied at the same time as the actual assessment is $\vec{\omega}$ constructed and all must then be approved by the $\frac{?}{2}$ year committee. This committee comprises the year $\bar{\emptyset}$ co-ordinator and the chairperson of the five domains $\vec{\bullet}$ of learning (professional skills, critical reasoning, management of illness, population medicine, self- $\hat{W}_{\tilde{W}}$ directed learning), as well as the chairpersons of ${ }^{\omega}$ each academic term. Following the assessment, 음 and before marking, the students from each year review both the assessment and the model answers, ${ }_{\mathbb{D}}$ to identify any factors which may have a bearing on $\mathbb{\Phi}_{\mathbb{D}}$ student performance, for example, ambiguity, time 3 allotted for each question, suggested variations to model answers and their marking. Student involve- $\vec{\bullet}$ ment at this stage in the written assessment phase occurs in the interests of fairness, and in recognition. of the fact that teaching, learning and its assessme⿳亠二口犬t are not always perfectly co-ordinated.

The MEQ format (Table 1) is similar to the simulated clinical-case-study format used to evalu- $\frac{0}{\varnothing}$

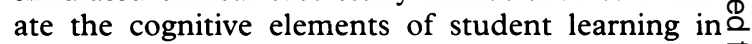
clinical ethics courses (12). In particular, the year- $\overrightarrow{\overrightarrow{0}}$ five MEQ was designed to evaluate student sensi-3 tivity to ethical issues (Qs $3,5 b$ ), knowledge of ethical concepts and arguments (Qs 3, 4a, 4b) and? the ability critically and ethically to reflect and justify (Qs $5 \mathrm{a}, \mathrm{c}$ and $\mathrm{d}$ ). The main strengths of this assessment tool are that it is objective, reasonably efficient and logistically feasible. There are, however, some minor problems. The most common of $\frac{0}{3}$ these tend to be associated with: student interpretation of questions; the number and weighting of the 9 ethical elements contained in the 'model' answers $\frac{?}{8}$ (prepared by HLE lecturers), and the level established for what is called a 'satisfactory' answer, $N$ which is based on a pre-set mandatory level of compe- $\mathrm{N}$ tence (MLC) - the minimum level of performance 0 acceptable for that question. The latter functions as $\omega$ a scoring guide for trained assessors. Experience in the construction and use of this form of assessment over the years, together with the pre-marking feedback from the student body has tended to minimise ${ }_{-}^{+}$ the impact of these types of problems. However, $\frac{0}{0}$ there remains a major weakness which cannot be

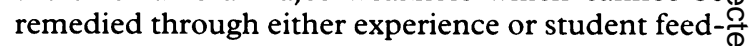
back, and that is, the limitation this very type of $\stackrel{\mathbb{}}{\circ}$ assessment tool places on what can be assessed.? Written, or even video-based assessments (13), pro- 


\section{Table 1: \\ End-of-year 'MEQ' assessment for year five: 1991}

Mrs VG, aged 48, has recently come into the care of the palliative care team with advanced breast cancer. She lives at home with her husband who is severely disabled. They have no family and few friends. Their home is a small Housing Commission house in Edgeworth. She is bed-bound. A nursing colleague rings to say she has a lot of pain, is very breathless and distressed.

You know she has widespread bone metastases in the lower spine, femora and ribs and a moderate sized pleural effusion, several lung metastases and patchy basal consolidation.

She is so distressed by pain and dyspnoea and her general life situation that she asks you to give her a 'shot so that I can die quickly'. Her husband who is there, agrees with her wish to end it all quickly.

\section{Question 3}

Mrs VG is still fearful and distressed by her and her husband's life; she is now narcotised with oral morphine. Each of these may have an effect on her ability to process information and/or make competent choices about medical treatment. How relevant is this to Mrs VG's request that you help her end it all quickly? Defend your answer, briefly.

(5 mins)

Question 4

No 'shot' is given, but Mrs VG develops pneumonia. Now, the issue for you is whether you should treat the infection with an antibiotic.

(a) Indicate three (3) general conditions for overriding the prima facie obligation to treat a patient like Mrs VG and define each briefly.

(b) Identify the weaknesses of the three (3) general conditions or situations when considered as guides for clinical ethical decision-making.

(10 mins)

\section{Students turn to next page}

The three general conditions for overriding the prima facie obligation to treat a patient like Mrs VG are:

1. Pointless treatment

2. Burdens outweigh benefit

3. Quality of life considerations

You inform Mrs VG that she has pneumonia and that it can be controlled with a course of antibiotics. Mrs VG leaves the decision to use or not use antibiotics to you. Her husband is in agreement.

\section{Question 5}

You decide not to treat Mrs VG with a course of antibiotics.

Discuss why you made this decision and in so doing:

(a) Indicate which of the three (3) general conditions for overriding the prima facie obligation to treat a patient is relevant in this case and why.

(b) Select the relevant details of Mrs VG's case which seem to justify your choice in (a) above.

(c) Identify objections to your choice in (a) above and your decision not to treat Mrs VG's pneumonia; and

(d) indicate briefly how you might respond to the objections identified in (c) above. 


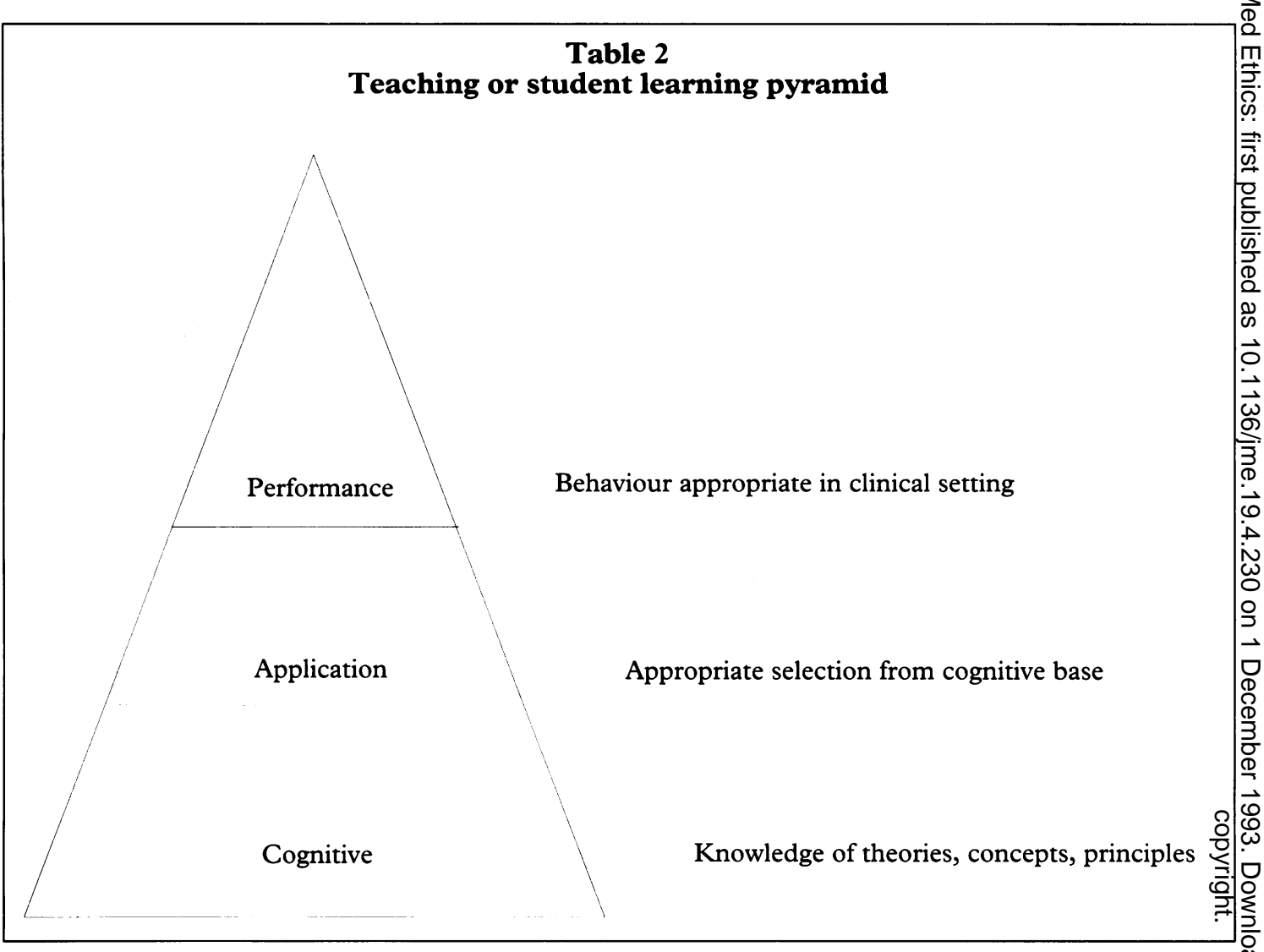

vide information on only one element of the student's clinical behaviour, ie, the knowledge base or the KNOW component.

\section{Clinical ethical competence}

Clinical ethical competence, like other forms of clinical competence $(14,15)$, involves far more than the demonstration of cognitive learning $(11,16)$. Cognitive tools may assess whether students have assimilated a core of facts and may provide some evidence of their ethical sensitivity, reflection, and reasoning process. They do not, however, adequately assess how students actually make clinical decisions such as when it is ethically (and legally) justified to treat an unwilling patient. Nor do they adequately assess: 1) the presence or absence of taught professional values such as respect for the patient's choices or 2) the quality of the student's communication with the patient, both of which are essential to the decision-making process.

A basic medical ethics curriculum should, it can be argued, do more than just cognitively sensitise students to ethical issues in medical practice. It should provide our future doctors with the conceptual, moral-reasoning, and interactional abilities to deal with most of the ethical issues raised by patients and their problems in daily practice in ways which improve the quality of their patient $\stackrel{\circ}{\stackrel{\Phi}{\Phi}}$ care. The acquisition of this type of competence $\overrightarrow{\vec{B}}$ has been described in terms of student learning or $\frac{3}{3}$ teaching as a pyramid (Table 2), with the cognitive or knowledge elements at the bottom, the ability to apply the knowledge in the middle, and performance or actual behaviour in the clinical context at ${ }_{\overparen{\Phi}}$ the top (17).

A simpler interpretation has been proposed, KNOW-CAN-DO (14). At the bottom, the student 0 shows that he/she knows how or what to do in knowledge terms. In the middle, the student 의 performs in a controlled and observed setting with $a \gg$ standardised stimulus such as a real or simulated을. patient. At the third level, and while unobserved, the N student performs in daily practice when no one is watching.

As with other clinical skills, the Know-Can-Dow model emphasises the interdependence of learning. The CAN facet of clinical ethical competence may,o however, take more learning or practice than the $\Phi$ KNOW facet, because it relies on other professional ${ }^{?}$ skills, such as interactional and medical interviewing skills, as the vehicle for its expression. The DO $\underset{\mathbb{\Phi}}{\stackrel{0}{0}}$ facet is probably more influenced by institutional demands, personal values, motivation and the avail- $\mathbb{Q}$ ability of suitable role models. These distinctions possess a real relevance for the assessment of clinical 


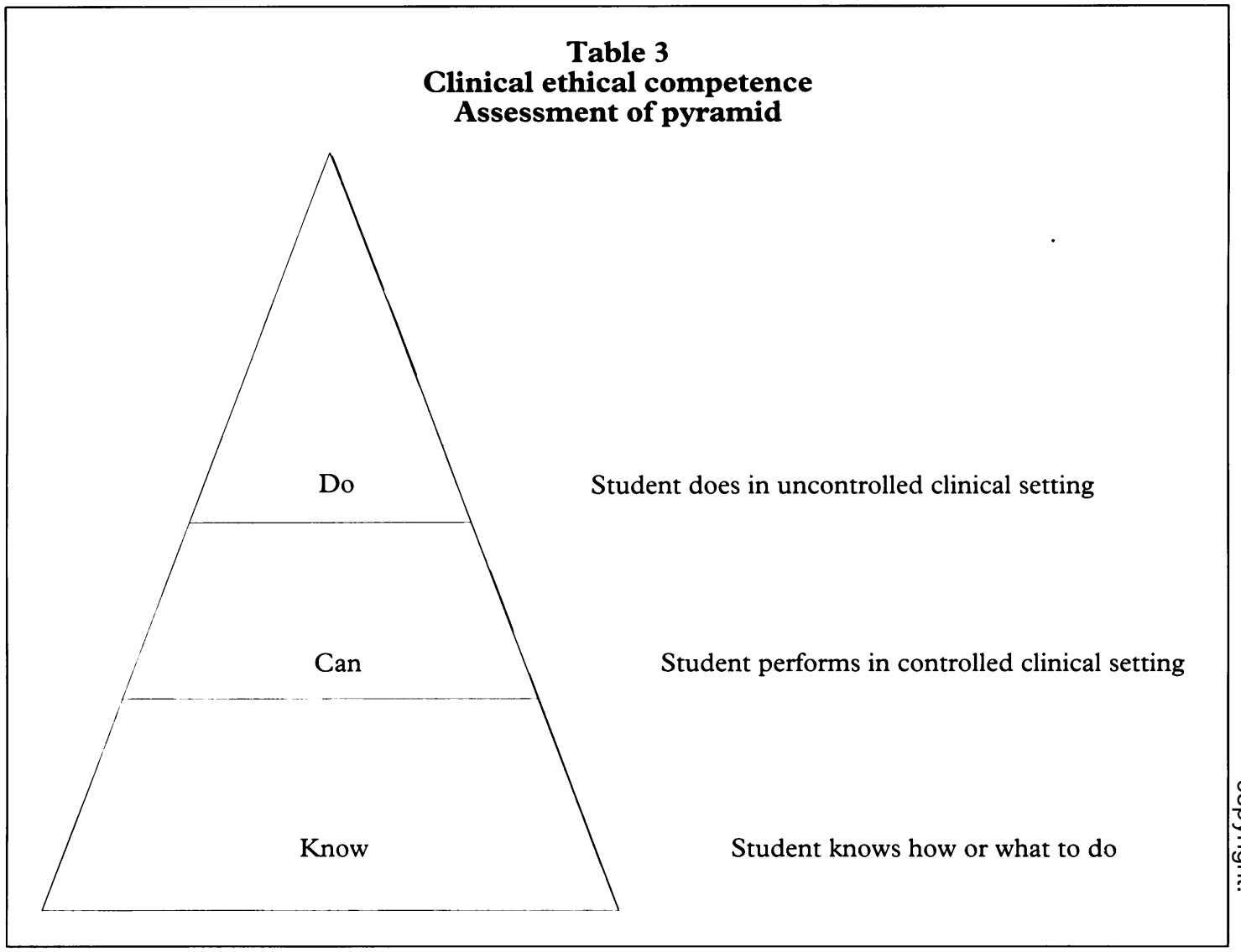

ethical competence. They also point the way to how we might answer what still remains a critical question: 'Does teaching ethics have a measurable effect on the clinical activity of medical students who have had such courses?' Furthermore, evaluations based on such assessments can and should influence our teaching methods and strategies.

\section{Assessment of clinical ethical competence}

The appropriate determination of student clinical ethical competence must necessarily involve a broader range of action-oriented assessment tools than seems to be the case now, or, at least, was the case at Newcastle up to 1991. However, construction and use of CAN and DO type tools to assess students' clinical ethical competence in clinical practice, has lagged behind the emergence and increasing importance of knowledge-based programmes in medical ethics in undergraduate curriculums. In particular, the assessment of DO in clinical medicine (chart reviews, chart stimulated recall) is poorly developed and inadequately evaluated. Fortunately, some of the already existing assessment methodology can be modified to measure the CAN part of the competence hierarchy. One such CAN-instrument is the objective structured clinical examination
(OSCE) which was first described in 1979 (18), and, when used in conjunction with a standardised scenario, has proved a reliable and valid method for assessing clinical skills (19).

The basic OSCE format consists of a series of standardised ten-minute stations at which each student is required to stop and perform some discipline-related action under controlled and observed conditions. Several disciplines are usually involved, with each discipline responsible for manning one or more stations. Scoring is carried out in real time. At the University of Newcastle the OSCE format has been used since the early 1980 s by both basic science and clinical disciplines and has proved a reliable and valid tool for assessing the CAN facet of student performance. A recent study (20) has now demonstrated that the OSCE format is equally useful in assessing competency to address ethical issues.

In 1992, we intend to commence the use of MEQ and OSCE instruments to assess both the KNOW and CAN facets of student clinical ethical competence. For example, by year four, our students possess reasonably competent interviewing skills and have frequent clinical contact with patients. They also attend seminars on ethical issues associated with informed consent, valid refusals, confidentiality and 
truth-telling. Assessment could therefore involve a) a 30-minute MEQ to assess what they know (8); and b) an OSCE to assess what they CAN do when confronted by a role-playing patient. The latter would occur by way of one, 10-minute station as part of their usual year-four OSCE examination.

By way of illustration, the OSCE station may confront the student with a patient who needs an important operation which has an associated minor, but life-disruptive risk. The patient has previously refused the operation, although there is some doubt about the patient's competence. The student's task may be, for example, to evaluate whether the patient is sufficiently competent to give a valid refusal. On past experience with OSCEs, we expect that the task illustrated above would provide adequate opportunity to examine students' selective application of knowledge from their ethical cognitive base in conjunction with the demonstration of taught professional values in the form of appropriate attitudes, affect and interactional skills. It should be noted that formal assessment of interactional skills already occurs in year four as part of a 'long case' assessment for the domain of professional skills. The ethics OSCEs would complement the initial assessment of interactional skills in a different context.

The logistics of mounting an OSCE station are formidable, even for a small faculty like Newcastle, which has only 60 year-four students. At a minimum, six examiners (two per station), would be needed to complete the assessment for 60 students spread over three hours. If, as we intend, OSCEs are eventually used in all five years of the curriculum, the 15 hours of assessment involved will necessitate the training and use of clinicians and faculty members who may not be involved in the actual teaching of the HLE strand. The problems this will entail, we believe, will be more than offset by the opportunity to involve more clinicians, as they, whether teachers of ethics or not, remain powerful role models for our students.

Assessing the DO facet of clinical ethical competence (Table 3) is a more difficult task. Does knowledge of what to do, or, a demonstration that the student can do something, predict performance in the practice setting? It cannot be assumed that the capacity to perform in a controlled test situation, where students are on their 'best behaviour', is equivalent to actual clinical-ethical reasoning and decision-making on the wards when not observed or controlled. Whereas long cases may increase concurrent validity, over and above the use of OSCEs alone, they do not necessarily possess validity predictive for either ethically or clinically appropriate behaviour in the unobserved work context.

\section{Conclusion}

The formal teaching of health law and ethics at Newcastle began in 1979 and was first assessed in 1982 by means of the modified essay question. The combination of a formal course and its examination, even in written form, was a sufficiently novel event in Australia to encourage those involved to focus their entire effort on improved teaching stratagems for $\vec{\equiv}$ student learning. No time remained for the equally important task of ensuring that student learning was being applied in clinical practice. However, the current visibility and increasing acceptability for medical ethics courses at the international level, $\unrhd$ served to sharpen our critical awareness of lingering $\approx$ questions in medical ethics training: 1) How should $\overrightarrow{0}$ clinical ethics be assessed? 2) What can this tell us about how clinical ethics should be taught? and, 3) What effect, if any, does such training have on the actual clinical behaviour of students?

After ten years, our clinical colleagues, quite $\vec{\oplus}$ properly, seek assurance that the investment of scarce educational resources will result in a satisfac- iv tory and measurable dividend. Clinicians argue that ${ }^{\circ}$ since they are held accountable for the quality of $\frac{\text { 의 }}{2}$ student clinical competence, so we, too, must see ourselves as accountable, or, at least partially so, for the ethical competence displayed by students in clinical practice. In 1992, we (and clinicians) were no longer confident that written examinations alone could guarantee the appropriate application of student knowledge in this area to the workplace. 8 tentative beginning therefore was made to redefin and assess the concept of clinical ethical competen in terms of what the student knows, can do an actually does, when no one is watching or assessing. The first two elements, we believe, can be examined by existing instruments at the undergraduate level. The latter element, DO, remains in need of thoughtful reflection and ingenuity and its assessment may well form part of resident and other postgraduate training programmes.

Finally, teaching ethical reasoning as an essential element of clinical case management requiring rigorous justification demonstrates to both students and clinicians that ethics is not 'irrelevant', 'culturally relative' or mere 'common sense', but rather a vital practical and professional skill. In a practical profession like medicine, clinical ethical competence, or, the 온 doing of ethics, enhances credibility as no amount of $\rightarrow$ study or talking about ethics can do.

\section{Acknowledgement}

We gratefully acknowledge the funding of Catherine $c$ Myser's position, which was provided by the NSW Medical Defence Union.

Kenneth $R$ Mitchell, MSc, MED, PhD, Grad Dip? RelSt, FAPsS, is Senior Lecturer in the Health Law and Ethics Programme, Faculty of Medicine, University of $\frac{\vec{D}}{\mathbb{D}}$ Newcastle, Australia. Catherine Myser, $M A, P h D$, is NSW Medical Defence Senior Lecturer, in the Health $₫$ Law and Ethics Programme, Faculty of Medicine, 으 University of Newcastle, Australia. Ian $H$ Kerridge, 
$B A, B M e d$ (Hons), MPhil, is Clinical Lecturer in the Health Law and Ethics Programme, Faculty of Medicine, University of Newcastle, Australia.

\section{References}

(1) Boyd K M, ed. Report of a working party on the teaching of medical ethics - The Pond report. London: IME Publications, 1987.

(2) Evans D. Health care ethics: a pattern of learning. fournal of medical ethics 1987; 13: 127-131.

(3) Calman K C, Downie R S. Practical problems in the teaching of ethics to medical students. Fournal of medical ethics 1987; 13: 153-156.

(4) Burling S J, Lumley J S P, McCarthy L S L et al. Review of the teaching of medical ethics in London medical schools. Fournal of medical ethics 1990; 16 : 206-209.

(5) Culver C M, Clouser K D, Gert B et al. Basic curricular goals in medical ethics. New England journal of medicine 1985; 312: 253-256.

(6) Walker R M, Lane L W, Siegler M. Development of a teaching program in clinical medical ethics at the University of Chicago. Academic medicine 1989; 64: 723-729.

(7) Seedhouse D F. Health care ethics teaching for medical students. Medical education 1991; 25: 230-237.

(8) Mitchell K R, Myser C, Lovat T J. Teaching bioethics to medical students: The Newcastle experience. Medical education (in press).

(9) Hebert P C, Meslin E M, Dunn E V, Byrne N, Reid $S$ R. Evaluating ethical sensitivity in medical students: using vignettes as an instrument. Fournal of medical ethics 1990; 16: 141-145.
(10) Health law and ethics strand. Clinical ethics and law: introductory document. Newcastle: Faculty of Medicine, 1992.

(11) Pellegrino E D, Siegler M, Singer P A. Teaching clinical ethics. Fournal of clinical ethics 1990; 1, 3: 175-180.

(12) Siegler M, Rezler A G, Connell K J. Using simulated case studies to evaluate a clinical ethics course for junior students. Fournal of medical education 1982; 57 : 380-385.

(13) Spooner $\mathrm{H} \mathrm{J}$, Haight $\mathrm{K}$ R, Emson $\mathrm{H}$ E, To $\mathrm{T}$. Assessment of medical students' learning and performance in an introductory medical ethics course. Teaching and learning in medicine. 1989; 3: 167-170.

(14) Norman G. Can an examination predict competence? The role of recertification in maintenance of competence. Annals of the Royal College of Physicians and Surgeons of Canada 1991; 24: 121-124.

(15) Weatherall D J. Examining undergraduate examinations. Lancet 1991; 338: 37-39.

(16) Hebert P C, Meslin E M, Dunn E V. Measuring the ethical sensitivity of medical students: a study at the University of Toronto. Fournal of medical ethics 1992; 18: 142-147.

(17) Miller G E. The assessment of clinical skills, competence, performance. Academic medicine [suppl] 1990; 65: 563-568.

(18) Harden R M, Gleeson F A. Assessment for clinical competence using an objective structured clinical examination. Medical education 1979; 13: 41-47.

(19) Cohen R. Comprehensive assessment of graduates of foreign medical schools. Annals of the Royal College of Physicians and Surgeons of Canada 1989; 21: 505-509.

(20) Cohen R, Singer P A, Rothman A I, Robb A. Assessing competency to address ethical issues in medicine. Academic medicine 1991; 66, 1: 14-15.

\section{News and notes}

\section{Association for the Advancement of Philosophy and Psychiatry}

The Association for the Advancement of Philosophy and Psychiatry (AAPP) is dedicated to philosophical inquiry in psychiatry. The AAPP aims to enhance the effectiveness of the psychiatrist as teacher, researcher, and practitioner by illuminating the philosophical issues embedded in these activities. The association also aims to encourage philosophical inquiry by making psychiatric phenomena more accessible to philosophers.

The AAPP is now five years old, and is seeking to expand its membership. In conjunction with the Royal College of Psychiatrists' philosophy group, the AAPP will begin publication of a new journal, Philosophy, Psychiatry, and Psychology (PPP) in 1994. This international journal, to be published by the Johns Hopkins University Press, is singular in its focus on philosophical aspects of psychiatry and clinical psychology. The journal is now seeking manuscript submissions.

Inquiries about both the AAPP and the PPP should be directed to: Linda Muncy, Administrative Secretary, AAPP, Department of Psychiatry, The University of Texas Southwestern Medical Center, 5323 Harry Hines Blvd, Dallas, TX 75235-9070. Telephone: (214) 648-3390. 